\title{
Parenting, identity development, internalizing symptoms, and alcohol use: a cross-sectional study in a group of Italian adolescents
}

This article was published in the following Dove Press journal:

Neuropsychiatric Disease and Treatment

18 July 2016

Number of times this article has been viewed

\section{Monica Pellerone \\ Giacomo Tolini \\ Caterina Polopoli}

Faculty of Human and Social Sciences, "Kore" University of Enna, Enna, Italy

Correspondence: Monica Pellerone Faculty of Human and Social Sciences, "Kore" University of Enna, Via Cittadella Universitaria, snc, Enna (En), 94100 , Italy

Tel +39329432 43II

Email monica.pellerone@unikore.it
Background: Literature has demonstrated the adaptive function of identity development and parenting toward manifestation of problem behaviors in adolescence. These dimensions act on both internalizing and externalizing symptoms.

Methods: The objective is to investigate the relationship between identity status, parenting, and adolescent problems, which may manifest through internalized (phobias, obsessions, depression, eating disorders, entropy) and externalized modes (alcohol use and school discomfort). The research involved 198 Italian students (104 males and 94 females) in the 4th year (mean $=16.94$ years, standard deviation $=0.35$ ) and 5 th year (mean $=17.94$ years, standard deviation $=0.43$ ) of senior secondary schools, who live in Caltanissetta, a town located in Sicily, Italy. The research lasted for 1 school year. The general group consisted of 225 students with a mortality rate of $12 \%$. They completed an anamnestic questionnaire to provide 1) basic information, 2) alcohol consumption attitude in the past 30 days, and 3) their beliefs about alcohol; the "Ego Identity Process Questionnaire" to investigate identity development; the "Parental Bonding Instrument" to measure the perception of parenting during childhood; and the "Constraints of Mind" to value the presence of internalizing symptoms.

Results: Data show that identity status influences alcohol consumption. Low-profile identity and excessive maternal control affect the relational dependence and the tendency to perfectionism in adolescents. Among the predictors of alcohol use, there are socioeconomic status, parental control, and the presence of internalizing symptoms.

Conclusion: Family is the favored context of learning beliefs, patterns, and values that affect the broader regulatory social environment, and for this reason, it is considered the privileged context on which to intervene to reduce the adolescents' behavior problems. This deviance could be an external manifestation of the difficulty in management of internalizing symptoms in adolescence.

Keywords: adolescence, parental control, internalizing and externalizing symptoms, constraints of mind, socioeconomic status

\section{Introduction}

This cross-sectional study investigates the possible relationship between identity development, parenting, and adolescent problems, which may manifest through internalized modes (phobias, obsessions, depression, eating disorders, entropy) and externalized ones (alcohol use and school discomfort), in a group of 198 Italian students.

Recent literature emphasizes the importance of examining the risk and protection factors for the internalizing and externalizing symptoms in adolescence, which appear in different contexts: social and interpersonal, such as family, school, and peer group; and individual factors, such as identity development, and cognitive and behavioral patterns. 
Compared to the interpersonal factors, ${ }^{1-4}$ studies show that a high level of parental control ${ }^{5-7}$ is related to a high level of adolescent's implication in problematic behaviors (such as alcohol abuse), ${ }^{8,9}$ above all in the age group between 18 and 19 years. ${ }^{10,11}$ Conversely, when the parental presence is significant and authoritative, the adolescents are better protected ${ }^{12,13}$ and the probability of risk-taking behavior decreases. ${ }^{14,15}$

In reference to the individual dimension, adolescence represents a crucial stage in the development of identity. According to Marcia's model, the psychosocial identity construct is defined as a dynamic structure and not a static one, whose formation depends on different factors such as the decisions taken during life. The styles through which identity problems are faced are classified into four identity statuses: achievement (characterized by positive self-image, flexibility, and cognitive independence), moratorium (fears for the future, limited flexibility, and reduced cooperation), foreclosure (conventionality, rigidity, low self-esteem, and conflictual relationships), and diffusion status (flexibility and cognitive complexity). ${ }^{14}$

Literature shows that less sophisticated identity status seems to be correlated with a higher level of alcohol consumption; ${ }^{15}$ so, adolescents with low level of development identity seem to be classified as binge drinkers and heavy drinkers.

However, the social and family dimensions can influence the early risk behavior experimentation in adolescence, but the outcome of these conditioning issues could have different consequences in relation to the individual features, such as identity development and the possible presence of internalizing symptoms. ${ }^{16-18}$

\section{Identity, parenting, and internalizing symptoms in adolescence}

During adolescence, development tasks can be faced without serious difficulties, and the overcoming of these development tasks (such as autonomy from parents, the comparison with peer group and the acquisition of useful tools to experience new roles) could be a significant factor of protection from possible evolutionary breakdown; ${ }^{19,20}$ but transitional or problematic states can lead the person to manifest internalizing symptoms, especially during adolescence. ${ }^{21,22}$ The main risk factors that seem to match with the development of internalizing symptoms are as follows: reduced identity development, ${ }^{23}$ lack of emotional support, ${ }^{24}$ frequent adoption of punitive parenting behavior, ${ }^{25,26}$ parental psychological control, ${ }^{27,28}$ and also disadvantaged sociocultural characteristics. ${ }^{29,30}$

Compared to parenting, adolescents exposed to parental psychological control seem to adopt the same rigorous and strict standards proposed by parents, living inadequately with the inability to reach the standards, both socially prescribed and those self-imposed. ${ }^{31,32}$ In particular, literature underlines the harmful effects of maternal control, which are less evident toward their daughters and more evident toward their sons, over the level of perfectionism in adolescent children. In the mother-daughter dyad, rather than perfectionism, it seems that the responsible mechanism for the link between controlling parenting and internalizing symptoms is relational dependency. ${ }^{33,34}$

Moreover, adolescents with low-profile identity (foreclosure and diffusion status) who find themselves living in an adverse family situation could experience a low perception of control over their environment, which may predispose them to develop the perception of reduced control over mental and physical states. ${ }^{35,36} \mathrm{In}$ fact, recent studies show how high levels of warmth or support are related to lower levels of internalization in adolescents with high-profile identity; ${ }^{37-39}$ on the other hand, excessive control and lack of parental empathy appear to be related to the onset of interior symptoms such as depression, anxiety, ${ }^{40-42}$ lack of self-control, or irritability in low-profile adolescents. ${ }^{43-45}$

In particular, the result of internalizing symptoms refers to the superimposition of anxious and depressive syndromes; ${ }^{46,47}$ the presence of anxiety symptoms and feelings of worry and depression in low-profile adolescents are associated with the feeling of being perceived negatively by parents. ${ }^{48,49}$ Even hypercontrol is interpreted by adolescents as the confirmation of a general devaluation by their parents. ${ }^{50-52}$

Recent research has made refusal and parental control effects more detailed and complex, highlighting how they may be related to both internalizing and externalizing symptoms. ${ }^{48,53}$ In particular, research has demonstrated the adaptive function of paternal empathy and support toward sons; ${ }^{54,55}$ these variables would act on both internalizing symptoms - such as anxiety, depression, impulse control - and externalizing symptoms - such as aggression, taking drugs, alcohol use, and school discomfort. In addition, some theories about deviance in adolescence argue that certain deviant behaviors, such as delinquency and alcohol use, are no more than external manifestations of a difficult management of internalizing symptoms. ${ }^{56}$

The objective of this study is to examine the relationship between identity, parenting, and adolescent problems, which may manifest through internalized modes and externalized ones in a group of adolescents. In light of the recent literature, we assumed the following research hypotheses: 1) identity development and, in particular, the importance 
conferred to values, religion, family, ${ }^{50,57}$ and friendship ${ }^{16}$ influence alcohol use in adolescents; ${ }^{57}$ 2) the presence of low-profile identity and excessive maternal control affect the relational addiction ${ }^{26}$ and the tendency to perfectionism; $; 2$ 3) a low-profile identity and paternal dysfunctional parenting in adolescent males influence the levels of phobia, obsession, depression, and entropy; ${ }^{35,58} 4$ ) among the predictors of the use of alcohol are socioeconomic status (SES), ${ }^{29,59}$ a low-profile identity, ${ }^{21,57}$ high parental control, $, 9,10,15,60$ and the presence of internalizing symptoms in adolescents. ${ }^{36}$

\section{Methods}

\section{Participants and procedure}

The research involved 198 Italian students (104 males and 94 females) in the 4 th year (mean $[\mathrm{M}]=16.94$ years, standard deviation $[\mathrm{SD}]=0.35)$ and 5 th year $(\mathrm{M}=17.94$ years, $\mathrm{SD}=0.43$ ) of senior secondary schools, who live in Caltanissetta, a town located in Sicily, Italy.

The research lasted for 1 year; the group of participants involved all students attending the last 2 years of high school, through authorization of headmasters and teachers. Administration of instruments took place during school timetable.

The general group of participants consisted of 225 students. Although all subjects agreed to be part of the research, there was a mortality rate of $12 \%$. This happened because the instruments were administered on 2 different days and the possible absence of students made it difficult to complete the compilation of all protocols.

The consent of the school authorities and the students involved in the study was sought before the distribution and collection of the instruments. The questionnaires were anonymous, and the participants were informed of the aim and structure of the study. All participants provided written informed consent.

The research was approved by the Internal Review Board of the Faculty of Human and Social Sciences at the "Kore" University of Enna.

\section{Measures}

Participants completed an anamnestic questionnaire, the Ego Identity Process Questionnaire, the Parental Bonding Instrument, and the Constraints of Mind.

Anamnestic data were collected through the administration of a questionnaire constructed ad hoc and divided into three parts: the first to acquire basic information, age, sex, year attended, academic qualifications and professions of parents; the second for establishing school performances, such as absences, permission to enter late or leave early, and marks obtained in the last 30 days; and the third for ascertaining the frequency of alcohol use, average number of drinks consumed per occasion in the past 30 days and the reasons for it, and the beliefs about alcohol use. The family's SES was defined by family income and education. Family income was defined on an eight-point scale, ranging from 700 Euros to 4,000 Euros per month. Family education was measured with the highest level of parents' education on a seven-point scale, ranging from primary school to a master's degree. ${ }^{61}$

The Ego Identity Process Questionnaire is a tool investigating the identity status development according to Marcia's model $^{31}$ through the dimensions of exploration and commitment. The exploration level is measured through the analysis of four ideological domains (occupation, religion, politics, and values), and the commitment level is investigated through four interpersonal domains (family, friendship, sex roles, and sentimental relationships). Literature reports the estimates of internal validity of the tool as 0.80 for the results that indicate commitment and 0.86 for the scores that indicate exploration; the scores that indicate reliability are 0.90 for commitment and 0.76 for exploration; the internal consistency is 0.72 and 0.71 for commitment and exploration, respectively. ${ }^{62}$

The Parental Bonding Instrument is a questionnaire consisting of 25 items, divided into two parts (one for the mother and the other one for the father), which retrospectively measure the perception of behavior of the parents during childhood. ${ }^{63}$ The instrument investigates the processes of parenting across two domains, parental care and control or overprotection, from the combination of which four types of attachment were classified: affectionate constraint: high scores in both scales; optimal parenting: high care and low protection; affectionless control: high protection and low care; and neglectful parenting: low care and low protection. Assignment to "high" or "low" categories of domains is based on the following cutoff scores: for mothers, a care score of 27.0 and a protection score of 13.5 are the minimum scores for inclusion in the "high" category; for fathers, a care score of 24.0 and a protection score of 12.5 are the cutoff points. The Italian adaptation reports the estimates of internal consistency of the tool as 0.75 for the results that indicate mother's care, 0.84 for the scores that indicate mother's overprotection, 0.83 for father's care, and 0.88 for father's overprotection. ${ }^{64}$

The Constraints of Mind is a questionnaire consisting of 150 items, which measures 30 mind constraints grouped into five topicals: ${ }^{65}$

- Phobias: catastrophism, frailty, risk avoidance, health apprehension, distrust of others, relational addiction; 
- Obsessions: perfectionism, emotional inhibition, fear of making mistakes, control, superstition, cleaning and contamination;

- Depression: failure, loneliness, inadequacy, forced esteem, compulsion to provide care for others, pessimism;

- Entropy: distrust, odd thoughts, perceptual social control, social isolation, deterministic causality, ambivalence;

- Diet: somatic discomfort, obsession of one's body, eating behavior, compulsive physical activity, dependence of other's judgment, relational dynamic.

Assignment to "high" or "low" categories of domains is based on the following cutoff scores: any score of 4 or more is considered meaningful (both the score of each mind constraint, that the score of each topical).

\section{Data analysis}

All analyses were conducted with Statistical Package for the Social Sciences 23.0 (IBM Corporation, Armonk, NY, USA).

In reference to preliminary data, $t$-test for independent samples was used to compare the mean between groups (males versus females). In reference to the mind constraints and alcohol consumption, multivariate analysis of variance (MANOVA) was conducted to verify the influence of independent variables (sex and age) on the identity and the mind constraints.

In order to verify the influence of ideological and interpersonal domains on the use of alcohol, univariate analysis of variance was carried out.

In order to verify if a low level of identity combined with excessive maternal control influences the relational dependence and the tendency to perfectionism, MANOVA was carried out.

The same analysis was carried out to verify if a low level of identity combined with dysfunctional paternal parenting influences the constraints of mind in the group of boys.

In order to explore the predictive variables of alcohol use, hierarchical regression for separate blocks was used: 1) sex, age, and SES in the first block; 2) the level of school performance in the second block; 3) parenting in the third block; and 4) mind constraints in the fourth block. Each block of independent variables was evaluated in terms of what they added to the explanation of the variability of the dependent variable at the time of their entry, evaluating the weight of all predictors.

\section{Results}

\section{Descriptive statistics}

A descriptive analysis was conducted in order to investigate the mind constraints, comparing the mean scores of boys and girls and the cutoff scores for the Italian population. In the participant group, all mind constraints had lower scores than the cutoff scores (Table 1). The $t$-test shows that in the entropy domain, boys had higher scores than girls in perceptual social control $(F=4.60 ; P<0.05)$; in the diet domain, girls reported average scores significantly higher than boys in somatic discomfort $(F=12.13 ; P<0.01)$.

Compared to alcohol consumption, $t$-test shows a significant difference for the variable sex $(t[14,54]=2.69$, $P<0.001)$ : boys reported monthly use of alcohol more frequently than girls (males: $\mathrm{M}=3.95, \mathrm{SD}=6.73$; females: $\mathrm{M}=1.95, \mathrm{SD}=0.28$ ).

MANOVA, done to verify the influence of independent variables on the ideological and interpersonal domains, emphasizes the main effect of age (Wilks's lambda $=0.92$, $F=2.30, P<0.05$ ), but no effect due to sex (Wilks's lambda $=0.86, F=1.22, P=$ not significant $[\mathrm{ns}])$. Breakdown of the univariate effects shows that older students got higher scores in the family dimension than younger ones $(F=3.40$, $P<0.05)$.

A further MANOVA done to verify the influence of independent variables on the mind constraints emphasizes a main effect linked to the sex variable (Wilks's lambda $=0.30, F=7.73, P<0.001$ ), age (Wilks's lambda $=0.31$, $F=1.55, P<0.01$ ), and SES (Wilks's lambda $=0.003$, $F=1.30, P<0.001)$. In reference to the sex variable, breakdown of the univariate effects shows differences in emotional inhibition $(F=4.93, P<0.05)$ and pessimism $(F=110.26$, $P<0.001)$ : Tukey's post hoc shows that boys obtained higher values in emotional inhibition than girls, who obtained higher scores in the pessimism dimension. In reference to age, there is a difference in the pessimism dimension $(F=14.23$, $P<0.001)$ : Tukey's post hoc shows that older adolescents manifested higher values in pessimism than those who were younger. In reference to SES, there are differences in pessimism $(F=11.34, P<0.001)$ and fear of making mistakes $(F=2.55, P<0.05)$; in particular, adolescents with a greater SES showed lower average scores in pessimism than the adolescents with low SES, who reported greater emotional inhibition.

\section{Preliminary data}

In reference to the first hypothesis, the analysis of variance shows that between the ideological dimensions, only politics $(F=4.56, P<0.01)$ and religion $(F=3.03, P<0.05)$ appear to influence alcohol use in adolescents; between the interpersonal dimensions, only the family $(F=2.93, P<0.05)$ seems to affect this risk behavior. The analysis of mean scores shows 
Table I M and SD of "the mind constraints" subscales in all participants

\begin{tabular}{|c|c|c|c|c|c|c|c|c|c|}
\hline \multirow[t]{2}{*}{ Subscales } & \multicolumn{2}{|c|}{ Males } & \multicolumn{2}{|c|}{ Females } & \multicolumn{2}{|c|}{ Levene's test } & \multicolumn{3}{|c|}{ Student's test } \\
\hline & $M$ & SD & $M$ & SD & $\boldsymbol{F}$ & $P$-value & $t$ & $d f$ & $P$-value \\
\hline \multicolumn{10}{|l|}{ Phobias } \\
\hline Catastrophism & 3.46 & 0.77 & 3.20 & 0.83 & 1.28 & 0.26 & 2.24 & 196 & 0.26 \\
\hline Frailty & 2.80 & 0.83 & 2.99 & 0.72 & 0.09 & 0.32 & -2.06 & 196 & 0.40 \\
\hline Risk avoidance & 2.42 & 0.79 & 2.37 & 0.84 & 0.09 & 0.77 & 0.50 & 196 & 0.62 \\
\hline Health apprehension & 2.38 & 0.90 & 2.50 & 0.93 & 0.04 & 0.84 & -0.95 & 196 & 0.35 \\
\hline Distrust of others & 3.22 & 0.86 & 0.31 & 0.72 & 2.10 & 0.15 & -0.79 & 196 & 0.43 \\
\hline Relational addiction & 3.32 & 0.88 & 3.70 & 0.91 & 0.07 & 0.79 & -2.92 & 196 & $<0.01$ \\
\hline \multicolumn{10}{|l|}{ Obsessions } \\
\hline Perfectionism & 3.99 & 0.85 & 3.96 & 0.75 & 1.64 & 0.20 & 0.30 & 196 & 0.76 \\
\hline Emotional inhibition & 3.13 & 0.92 & 2.83 & 0.95 & 0.57 & 0.45 & 2.19 & 196 & 0.03 \\
\hline Fear of making mistakes & 3.60 & 0.83 & 3.59 & 0.71 & 2.11 & 0.15 & 0.05 & 196 & 0.96 \\
\hline Control & 3.50 & 0.96 & 3.16 & 1.05 & 0.53 & 0.47 & 2.38 & 196 & 0.02 \\
\hline Superstition & 2.99 & 0.84 & 3.06 & 0.84 & 0.20 & 0.65 & -0.59 & 196 & 0.55 \\
\hline Cleaning and contamination & 2.05 & 0.72 & 3.07 & 0.77 & 0.04 & 0.85 & -1.13 & 196 & 0.26 \\
\hline \multicolumn{10}{|l|}{ Depression } \\
\hline Failure & 2.70 & 0.99 & 2.85 & 0.93 & 0.63 & 0.43 & -1.17 & 196 & 0.25 \\
\hline Loneliness & 3.03 & 0.99 & 2.85 & 0.93 & 1.71 & 0.19 & -0.26 & 196 & 0.80 \\
\hline Inadequacy & 2.65 & 1.06 & 2.86 & 0.99 & 0.67 & 0.41 & -1.44 & 196 & 0.15 \\
\hline Forced esteem & 3.16 & 0.81 & 3.16 & 0.84 & 0.15 & 0.70 & -0.01 & 196 & 0.99 \\
\hline Compulsion to provide care & 3.36 & 0.84 & 3.60 & 0.79 & 0.48 & 0.49 & -2.07 & 196 & 0.04 \\
\hline Pessimism & 3.07 & 2.26 & 3.20 & 0.93 & 1.84 & 0.18 & -0.52 & 196 & 0.60 \\
\hline \multicolumn{10}{|l|}{ Entropy } \\
\hline Distrust & 2.81 & 2.00 & 2.50 & 0.70 & 1.53 & 0.22 & $1.4 \mathrm{I}$ & 196 & 0.16 \\
\hline Odd thoughts & 2.41 & 0.77 & 2.15 & 0.70 & 1.01 & 0.32 & 2.51 & 196 & 0.01 \\
\hline Perceptual social control & 1.57 & 0.70 & 1.47 & 0.54 & 4.60 & 0.05 & 1.24 & 196 & 0.22 \\
\hline Social isolation & 1.69 & 0.84 & 1.60 & 0.70 & 3.13 & 0.08 & 0.88 & 196 & 0.38 \\
\hline Deterministic causality & 2.85 & 0.63 & 2.83 & 0.64 & 0.00 & 0.96 & 0.05 & 196 & 0.96 \\
\hline Ambivalence & 2.70 & 0.83 & 2.89 & 0.80 & 0.36 & 0.55 & -1.63 & 196 & 0.10 \\
\hline \multicolumn{10}{|l|}{ Diet } \\
\hline Somatic discomfort & 1.79 & 0.70 & 2.37 & 1.05 & 12.13 & $<0.00$ & -4.61 & 196 & $<0.001$ \\
\hline Obsession of one's body & 2.48 & 0.63 & 2.80 & 0.74 & 2.53 & 0.11 & -3.30 & 196 & $<0.01$ \\
\hline Eating behavior & 2.03 & 0.55 & 3.14 & 0.63 & 1.88 & 0.17 & -1.26 & 196 & 0.21 \\
\hline Compulsive physical activity & 2.43 & 0.94 & 2.37 & 0.98 & 0.46 & 0.50 & 0.42 & 196 & 0.67 \\
\hline Dependence of other's judgment & 2.65 & 0.69 & 2.84 & 1.90 & 2.42 & 0.12 & -0.96 & 196 & 0.34 \\
\hline Relational dynamic & 2.28 & 0.66 & 2.44 & 0.61 & 0.08 & 0.78 & -1.86 & 196 & 0.06 \\
\hline
\end{tabular}

Notes: $P<0.00$ I, two-tailed; $P<0.01$, two-tailed; $P<0.05$, two-tailed. The research involved I 98 Italian students (I04 males and 94 females) in the 4 th year ( $M=16.94$ years, $\mathrm{SD}=0.35)$ and 5 th year $(M=17.94$ years, $S D=0.43)$ of senior secondary schools, who live in Caltanissetta, a town located in Sicily, Italy.

Abbreviations: $d f$, degrees of freedom; $M$, mean; SD, standard deviation.

how adolescents who give more emphasis to politics, religion, and family, respectively, declare a lower level of alcohol consumption. The data confirm, in part, the first research hypothesis because the importance conferred to friendship does not seem to affect alcohol use in adolescents.

In confirmation of the second research hypothesis, MANOVA shows the main effect of identity (Wilks's lambda $=0.41, F=1.46, P<0.05)$ and the type of parenting mother (Wilks's lambda $=0.001, F=0.32, P<0.05$ ) and no interaction effect (Wilks's lambda $=0.65 ; F=0.92, P=\mathrm{ns}$ ). The univariate effect shows how the identity influences relational addiction $(F=5.11, P<0.01)$, perfectionism ( $F=3.20, P<0.05)$, fear of error $(F=2.78, P<0.05)$, sense of inadequacy $(F=2.95, P<0.05)$, and compulsion to provide care for others $(F=3.83, P<0.05)$. Tukey's post hoc shows that students in foreclosure status have the highest average scores in relational addiction, the fear of making mistakes, and the compulsion to care; students in achievement manifest a greater perfectionism; and those in moratorium perceive greater sense of inadequacy. The type of maternal parenting seems to affect significantly the following constraints: distrust of others $(F=4.90, P<0.01)$, relational addiction 
Table 2 Model summary of hierarchical regression analyses that predicts alcohol use in the group of adolescents

\begin{tabular}{|c|c|c|c|c|c|c|c|}
\hline Model & Variable & $R^{2}$ & Adjusted $R^{2}$ & SE & $\beta$ & $t$ & $P$-value \\
\hline \multirow[t]{3}{*}{1} & Sex & 0.16 & 0.14 & 0.74 & -0.16 & -2.32 & $<0.01$ \\
\hline & Age & & & 0.59 & 0.22 & 3.29 & 0.02 \\
\hline & SES & & & 0.34 & 0.28 & 4.03 & $<0.001$ \\
\hline \multirow[t]{5}{*}{2} & Sex & 0.17 & 0.15 & 0.74 & -0.17 & -2.42 & 0.02 \\
\hline & Age & & & 0.59 & 0.22 & 3.20 & $<0.01$ \\
\hline & SES & & & 0.34 & 0.28 & 4.08 & $<0.00$ I \\
\hline & School performance & & & 0.00 & 0.12 & 1.77 & 0.08 \\
\hline & Absences & & & 0.16 & 0.04 & 0.56 & 0.58 \\
\hline \multirow[t]{9}{*}{3} & Sex & 0.19 & 0.14 & 0.77 & -0.16 & -2.34 & 0.02 \\
\hline & Age & & & 0.59 & 0.21 & 3.12 & $<0.01$ \\
\hline & SES & & & 0.34 & 0.28 & 4.07 & $<0.001$ \\
\hline & School performance & & & 0.01 & 0.11 & 1.56 & 0.12 \\
\hline & Absences & & & 0.16 & 0.03 & 0.49 & 0.62 \\
\hline & Maternal control & & & 0.08 & -0.05 & -0.62 & 0.54 \\
\hline & Maternal care & & & 0.09 & -0.02 & -0.27 & 0.79 \\
\hline & Paternal control & & & 0.08 & 0.08 & 0.90 & 0.37 \\
\hline & Paternal care & & & 0.07 & -0.07 & -0.89 & 0.37 \\
\hline \multirow[t]{14}{*}{4} & Sex & 0.21 & 0.15 & 0.83 & -0.12 & -1.59 & 0.11 \\
\hline & Age & & & 0.61 & 0.24 & 3.45 & $<0.01$ \\
\hline & SES & & & 0.35 & 0.26 & 3.80 & $<0.001$ \\
\hline & School performance & & & 0.01 & 0.11 & 1.55 & 0.12 \\
\hline & Absences & & & 0.16 & 0.01 & 0.12 & 0.91 \\
\hline & Maternal control & & & 0.08 & -0.06 & -0.65 & 0.52 \\
\hline & Maternal care & & & 0.09 & -0.05 & -0.65 & 0.52 \\
\hline & Paternal control & & & 0.08 & 0.09 & 0.97 & 0.33 \\
\hline & Paternal care & & & 0.07 & -0.07 & -0.87 & 0.39 \\
\hline & Phobias & & & 0.19 & -0.00 & -0.04 & 0.97 \\
\hline & Obsessions & & & 0.19 & 0.03 & 0.33 & 0.74 \\
\hline & Depression & & & 0.14 & 0.20 & -2.17 & 0.03 \\
\hline & Entropy & & & 0.18 & 0.14 & 1.41 & 0.16 \\
\hline & Diet & & & 0.16 & -0.07 & -0.84 & 0.40 \\
\hline
\end{tabular}

Notes: The research involved 198 Italian students ( 104 males and 94 females) in the 4 th year $(M=16.94$ years, $S D=0.35)$ and 5 th year $(M=I 7.94$ years, $S D=0.43)$ of senior secondary schools, who live in Caltanissetta, a town located in Sicily, Italy.

Abbreviations: $\beta$, beta standardized coefficients; M, mean; SD, standard deviation; SE, standard error; SES, socioeconomic status.

( $F=3.26, P<0.05)$, sense of failure $(F=5.25, P<0.01)$, pes$\operatorname{simism}(F=3.13, P<0.05)$, distrust $(F=4.29, P<0.01)$, social control $(F=4.24, P<0.01)$, social isolation $(F=3.28, P<0.05)$, and ambivalence $(F=6.50, P<0.001)$. Tukey's post hoc shows that adolescents with affectionless control parenting show higher scores in relational dependence, sense of failure, mistrust for the next, perceptual social control, isolation, and ambivalence; otherwise, adolescents with neglectful parenting manifest higher levels of mistrust of others.

In reference to the third hypothesis, MANOVA shows the effect of parenting (Wilks's lambda $=0.65, F=1.85$, $P<0.05)$ on the following symptoms: catastrophism $(F=3.45$, $P<0.05)$, health apprehension $(F=3.56, P<0.05)$, distrust of others $(F=04.03, P<0.05)$, relational addiction $(F=3.09$, $P<0.05)$, emotional inhibition $(F=4.99, P<0.01)$, superstition $(F=3.17, P<0.05)$, failure $(F=3.78, P<0.05)$, inadequacy $(F=4.83, P<0.01)$, and social isolation $(F=2.99, P<0.05)$, depending on other's judgment $(F=5.05, P<0.01)$ and relational dynamic $(F=3.18, P<0.05)$. Tukey's post hoc shows that adolescent boys with neglectful parenting have high scores in the aforementioned symptoms except two, sense of failure and inadequacy, which are manifested by boys with affectionate constraint parenting. It, therefore, seems to confirm the third research hypothesis.

In reference to the last hypothesis, hierarchical regression with separate blocks shows that the predictors of alcohol consumption are (Table 2): sex, age, SES, the level of depression, and entropy ( $21.2 \%$ of the overall variance explained). The data seem to confirm the last research hypothesis.

\section{Discussion}

The study investigates the possible relationship between identity development, parenting, and internalizing-externalizing symptoms during adolescence. It involves 198 Italian 
students, aged between 16 and 19, who live in Caltanissetta, a town located in Sicily, Italy.

As a partial confirmation of the first research hypothesis, identity seems to influence alcohol use in adolescents. In coherence with the literature, ${ }^{50,57}$ adolescents who confer greater importance to politics, religion, and family reduce their use of alcohol, although the dimension of friendship does not seem to influence the risk behavior. Probably, the partial confirmation of the hypothesis is due to the age of the participants, characterized by instability typical of adolescence. ${ }^{19,21}$

As the second research hypothesis states, both identity and the type of parenting affect internalizing symptoms, in particular. Adolescents in the foreclosure status manifest greater compulsion to caregiving with a resulting relational addiction and fear of error, probably due to the lack of critical evaluation of the various identity alternatives. ${ }^{26,32}$ Students in moratorium status perceive a greater sense of inadequacy, typical of those who have started an exploration path of the possible identity alternatives, without assuming any commitment yet. ${ }^{14,19}$ At least, the adolescents in achievement show high levels of perfectionism; this finding could be explained by the fact that in Sicilian culture, roles within the family are highly emphasized and adolescents have a strong need to meet parental and social expectations. ${ }^{66-68}$ This process, which is very common among South Italians, to make a good impression (fare bella figura) when interacting with other people, is very much a matter of showing integrity and bringing people to have respect for them; when they are not able to adopt to social pressure that is, when they make a "bad impression" - people feel ashamed. So, exposure to perfectionism and to an authoritarian parenting style may bring the adolescent to the perception of rigorous expectations, self-esteem linked to success, and fear of disappointing others. ${ }^{69}$

In confirmation of the third hypothesis, adolescent boys with paternal parenting marked by excessive control would perceive a greater sense of failure and inadequacy in dealing with everyday problems, which is typical in adolescence. ${ }^{70}$

The latest research hypothesis seems to be confirmed as well. Among the predictor variables to the use of alcohol, there are environmental and temperamental factors. In particular, it seems that the older kids with greater emotional inhibition and perception of external control consume more alcohol; such a risky behavior is shown mainly by people belonging to higher SES, or in families whose parents have a good level of education and culture, and high professional status, which is in disagreement with the international literature. ${ }^{71,72}$ In fact, there was little empirical evidence to support the commonly held view that social deprivation or low SES is associated with belated and reduced alcohol use. In reference to the relationship between low SES and alcohol consumption, there may be two opposing mechanisms. ${ }^{73}$ First, social deprivation is associated with almost all forms of morbidity and mortality. ${ }^{74}$ The second mechanism underlines that individuals with more money can afford more alcohol because there is a consistent inverse relationship across time between the cost of alcohol and the amount consumed. Our data support the second mechanism and appear to confirm the recent research conducted by the Organization for Economic Cooperation and Development, according to which in economically developed countries, such as Italy, the consumption of alcohol is higher among young people.

\section{Conclusion}

Based on the results described herein, it is appropriate to emphasize the limits of this work, namely, the absence of a sampling method, which prevents the presence of a representative sample, generalization of the results, and external validity. An additional limitation is the absence of a longitudinal-type study design, which is more suitable for research involving adolescents and their identity development.

Finally, the absence of a cross-sectional survey method makes it difficult to determine if the adverse relational family conditions (eg, low support or high control) are antecedents, links, or consequences of the antisocial behavior of children.

Therefore, identification of risk factors in individuals or in their environment is not enough to predict the future development, but it is necessary to consider the way in which certain features interact with the environment, modifying it and being, in turn, influenced by it. It is necessary, in other words, to take into consideration the features of the subject, the features of the environment, and the way in which these two sets of influences interact over time. ${ }^{75}$

Researchers have underlined the importance of parent training interventions for adolescents with alcohol use and comorbidity of externalizing and internalizing disorders. ${ }^{76,77}$ Participation in parent training, in fact, increased parental monitoring ${ }^{78}$ and decreased family conflict adolescent substance use and adolescent behavior problems. ${ }^{79}$

\section{Disclosure}

The authors report no conflicts of interest in this work.

\section{References}

1. Gerbino M, Pastorelli C, Vecchio GM, Paciello M, Tramontano C. Fattori di protezione e di rischio nell'uso di alcol e droga in adolescenza [Protective and risk factor for alcohol and drug abuse in adolescence] Psicol Clin Dello Sviluppo. 2005;3:415-436. [Italian.] 
2. Noller P, Callan V. The Adolescent in the Family. London: Routledge; 1991:235-270.

3. Baumrind D. Effective parenting during the early adolescent transition. In: Cowan PA, Hetherington EM, editors. Family Transitions. Advances in Family Research Series. Hillsdale, NJ: Erlbaum; 1991:111-163.

4. Maccoby EE, Martin JA. Socialization in the context of the family: parent-child interaction. In: Mussen PH, editor. Charmichael's Manual of Child Psychology. New York, NY: Wiley; 1983:158-185.

5. Youniss J, De Santis JP, Henderson SH. Parents' cognitions and developmental changes in relationships during adolescence. In: Sigel IE, McGillicuddy-De Lisi AV, Goodnow JJ, editors. Parental Belief Systems: The Psychological Consequences for Children. Hillsdale, NJ: Erlbaum; 1992:199-218.

6. Ciairano S, Bonino S, Jackson S, Miceli R. Stile educativo genitoriale e benessere psicosociale in adolescenza [Parental educational style and psychosocial well-being in adolescence]. Età Evol. 2001;69:61-71. [Italian.]

7. Pellerone $\mathrm{M}$, Miccichè S. Psychiatric symptoms and psychological distress in patients suffering from advanced cancer and in those considered "cured". The role of parenting and family relationship. Psychol Res. 2015;4(5):269-277.

8. Pellerone M. Time perception in children with developmental dyscalculia. Procedia Soc Behav Sci. 2013;103:1220-1227.

9. Bonino S, Cattelino E, Ciairano S. Adolescenti e rischio [Adolescents and risk]. Firenze: Giunti; 2003:37-52. [Italian.]

10. Di Clemente RJ, Wingood GM, Crosby R, et al. Parental monitoring: association with adolescent risk behaviors. Pediatrics. 2001;107: 1363-1368.

11. Beyers JM, Bates JE, Pettit GS, Dodhe KA. Neighborhood structure, parenting processes, and the development of youths' externalizing behaviors: a multilevel analysis. Am J Community Psychol. 2003;31(1-2): $35-53$.

12. Vieno A, Mirandola M. Uso di sostanze alcoliche e stili genitoriali: quale relazione nell'epoca di trasformazione della famiglia [Use of alcoholic beverages and parenting styles: what relationship the era of the family transformation]. Psicol Comunità. 2006;1(2):29-41. [Italian.]

13. Vieno A, Pastore M. Il ruolo dei genitori nel favorire l'apertura dei figli durante la pre-adolescenza [The role of parents in promoting the opening of the children during pre-adolescence]. Giornale Ital Psicol. 2009;36:565-580. [Italian.]

14. Pellerone M. Influence of identity, congruence of interest and coping strategy on decision making. Procedia Soc Behav Sci. 2015;191: 1344-1348.

15. Cattelino E, Calandri E, Bonino S. Il contributo della struttura e del funzionamento della famiglia nella promozione del benessere di adolescenti di diverse fasce di età [The contribution of the structure and functioning of the family in promoting the well-being of adolescents of different age groups]. Età Evol. 2001;69:49-60. [Italian.]

16. Kiesner J, Poulin F, Dishion TJ. Adolescent substance use with friends: moderating and mediating effects of parental monitoring and peer activity contexts. MerrillPalmer Q (Wayne State Univ Press). 2010;56: 529-556.

17. Craparo G, Gori A, Mazzola E, Petruccelli I, Pellerone M, Rotondo G. Posttraumatic stress symptoms, dissociation, and alexithymia in an Italian sample of flood victims. Neuropsychiatr Dis Treat. 2014;10: 2281-2284.

18. Scrimali T, Alaimo S, Grasso F. Dal Sintomo ai Processi. L'orientamento Costruttivista e Complesso in Psicodiagnostica [From symptom to processes. The constructivist and complex orientation in psychodiagnostics]. Milano: Franco Angeli; 2007:17-34. [Italian.]

19. Pellerone M, Passanisi A, Bellomo MFP. Identity development, intelligence structure, and interests: a cross-sectional study in a group of Italian adolescents during the decision-making process. Psychol Res Behav Manag. 2015;8:239-249.

20. Pellerone M, Spinelloa C, Sidoti A, Miccichè S. Identity, perception of parent-adolescent relation and adjustment in a group of university students. Procedia Soc Behav Sci. 2015;190:459-464.
21. Laghi F, Baiocco R, Attanasi S, D’Alessio M. Stati di identità e benessere psicologico in adolescenza [States of identity and psychological well-being in adolescence]. Età Evol. 2009;93:7-19.

22. Pellerone M, Bellomo M. Racial identity and disability: the perception of the "Other" in a group of Italian school teachers. Procedia Soc Behav Sci. 2015;197:161-166.

23. Barber BK, Harmon EL. Violating the self: parental psychological control of children and adolescents. In: Barber BK, editor. Intrusive Parenting: How Psychological Control Affects Children and Adolescents. Washington DC: American Psychological Association; 2002:156-192.

24. Barber BK. Parental psychological control: revisiting a neglected construct. Child Dev. 1996;67:3296-3319.

25. Grolnick WS. The Psychology of Parental Control: How Well-meant Parenting Backfires. Mahwah, NJ: Erlbaum; 2003:159-187.

26. Grolnick WS, Gurland ST, DeCourcey W, Jacob K. Antecedents and consequences of mothers' autonomy support: an experimental investigation. Dev Psychol. 2002;38:143-155.

27. Mills RSL, Freeman WS, Clara IP, Elgar FJ, Walling BR, Mak L. Parent proneness to shame and the use of psychological control. J Child Fam Stud. 2007;16:359-374.

28. Pomerantz EM, Eaton MM. Maternal intrusive support in the academic context: transactional socialization processes. Dev Psychol. 2001;37:174-186.

29. Adler NA, Boyce T, Chesney MA, et al. Socioeconomic status and health: the challenge of the gradient. Am Psychol. 1994;49:15-24.

30. Mendelson L, Kubzansky D, Geetanjali DD, Buka SL. Relation of female gender and low socioeconomic status to internalizing symptoms among adolescents: a case of double jeopardy? Soc Sci Med. 2008;66: 1284-1296.

31. Flett GL, Hewitt PL, Oliver JM, MacDonald S. Perfectionism in children and their parents: a developmental analysis. In: Flett GL, Hewitt PL, editors. Perfectionism: Theory, Research, and Treatment. Washington, DC: American Psychological Association; 2002:274-296.

32. Soenens B, Elliot AJ, Goossens L, Vansteenkiste M, Luyten P, Duriez B. The intergenerational transmission of perfectionism: parents' psychological control as an intervening variable. J Fam Psychol. 2005; 19(3):358-366

33. Blatt SJ. Experiences of Depression: Theoretical, Research and Clinical Perspectives. Washington, DC: American Psychological Association; 2004:353-465.

34. Patrizi C, Rigante L, De Matteis E, Isola L, Giamundo V. Caratteristiche genitoriali e stili di parenting associati ai disturbi internalizzanti in età evolutiva [Parenting characteristics and parenting styles associated with externalizing disorders in children]. Psichiatr Psicoterap. 2010;29(2):63-77. [Italian.]

35. Mclaughlin KA, Hatzenbuehler ML. Stressful life events, anxiety sensitivity, and internalizing symptoms in adolescents. $J$ Abnorm Psychol. 2009;118(3):659-669.

36. Greenberger E, Chen C, Tally SR, Dong Q. Family, peer, and individual correlates of depressive symptomatology among U.S. and Chinese adolescents. J Consult Clin Psychol. 2000;68(2):209-219.

37. Laible DJ, Carlo G, Raffaelli M. The differential relations of parent and peer attachment to adolescent adjustment. $J$ Youth Adolesc. 2000; 29(1):45-59.

38. Buist KL, Dekovic M, Meeus W, Van Aken MAG. The reciprocal relationship between early adolescent attachment and internalizing and externalizing problem behaviour. $J$ Adolesc. 2004;27:251-266.

39. Reitz E, Dekovic M, Meijer AM, Rutger CME. Longitudinal relations among parenting, best friends, and early adolescent problem behavior testing bidirectional effects. $J$ Early Adolesc. 2006;26:272-295.

40. Crocetti E, Klimstra T, Keijsers L, Hale WW, Meeus W. Anxiety trajectories and identity development in adolescence: a five-wave longitudinal study. J Youth Adolesc. 2009;38:839-849.

41. Crocetti E, Rubini M, Meeus W. Capturing the dynamics of identity formation in various ethnic groups: development and validation of a three-dimensional model. $J$ Adolesc. 2008;31:207-222. 
42. Schwartz SJ, Beyers W, Luyckx K, et al. Examining the light and dark sides of emerging adults' identity: a study of identity status differences in positive and negative psychosocial functioning. $J$ Youth Adolesc. 2011;40(7):839-859.

43. Kirkcaldy B, Siefen G, Furnham A. Gender, anxiety-depressivity and self-image among adolescents. Eur Psychiatry. 2003;18(2):50-58.

44. Parker GB, Barrett EA, Hickie IB. From nurture to network: examining links between perceptions of parenting received in childhood and social bonds in adulthood. Am J Psychiatry. 1992;149(7):877-885.

45. Steinhausen HC, Metzke CW. Prevalence of affective disorders in children and adolescents: findings from the Zurich epidemiological studies. Acta Psychiatr Scand. 2003;108:20-23.

46. Crawford TN, Cohen P, Midlarsky E, Brook JS. Internalizing symptoms in adolescents: gender differences in vulnerability to parental distress and discord. J Res Adolesc. 2001;11(1):95-118.

47. Lonigan CJ, Carey MP, Finch AJ. Anxiety and depression in children and adolescents: negative affectivity and the utility of self-reports. J Consult Clin Psychol. 1994;62(5):1000-1008.

48. Muris P, Merckelbach H, Mayer B, Snieder N. The relationship between anxiety disorder symptoms and negative self-statements in normal children. Soc Behav Pers. 1998;26(3):307-316.

49. Rapee RM, Heimberg RG. A cognitive-behavioral model of anxiety in social phobia. Behav Res Ther. 1997;35(8):741-756.

50. Marta E, Lanz M, Manzi C, Tagliabue S, Pozzi M, Bertoni A. La relazione genitori-adolescenti: un predittore della devianza? [The parent-adolescent relationship: a predictor of deviance?]. Psicol Clin Sviluppo. 2004;8(2):269-288. [Italian.]

51. Pellerone M, Craparo G, Tornabuoni Y. Relationship between parenting and cognitive schemas in a group of male adult offenders. Front Psychol. 2016;7:302.

52. Dugas MJ, Ladouceur R, Leger E, et al. Group cognitive-behavioral therapy for generalized anxiety disorder: treatment outcome and longterm follow-up. J Consult Clin Psychol. 2003;71:821-825.

53. Muris P, Meesters C, van den Berg F. The Strengths and Difficulties Questionnaire (SDQ)-further evidence for its reliability and validity in a community sample of Dutch children and adolescents. Eur Child Adolesc Psychiatry. 2003;12(1):1-8.

54. Lewis C, Lamb ME. Fathers' influences on children's development: the evidence from two-parent families. Eur J Psychol Edu. 2003;2: 211-228.

55. Crockett LJ, Eggebeen DJ, Hawkins AJ. Fathers' presence and young children's behavioral and cognitive adjustment. J Fam Issues. 1993;14: 355-377.

56. Helstrom A, Bryan A, Hutchison KE, Riggs PD. Tobacco and alcohol use as an explanation for the association between externalizing behavior and illicit drug use among delinquent adolescents. Prev Sci. 2004; 5(4):267-277.

57. Laghi F, Lonigro A, Baiocco R, Baumgartner E. The role of parenting styles and alcohol expectancies in teen bing and drinking. A preliminary investigation among Italian adolescents and their parents. Drugs Educ Prev Pol. 2013;20:131-139.

58. Venkatraman S, Dishion TJ, Kiesner J, Poulin F. Cross-cultural analysis of parental monitoring and adolescent problem behavior: theoretical challenges of model replication when East meets West. In: Guilamo-Ramos V, Jaccard J, Dittus P, editors. Parental Monitoring of Adolescents: Current Perspectives for Researchers and Practitioners. New York, NY: Columbia University Press; 2010:90-123.

59. Huckle T, You RQ, Casswell S. Socio-economic status predicts drinking patterns but not alcohol-related consequences independently. Addiction. 2010;105(7):1192-1202.

60. Trincas R, Patrizi M, Couyoumdjian A. Parental monitoring e comportamenti a rischio in adolescenza: una revisione critica della letteratura [Parental monitoring and risk behavior in adolescence: a critical review of the literature]. Psicol Clin Sviluppo. 2008;(3):401-435. [Italian.]
61. Hollingshead AB. Four factor index of social status. Yale J Sociol. 2011;8:21-52.

62. Balistreri E, Busch-Rossnagel NA, Geisinger KF. Development and preliminary validation of the Ego Identity Process Questionnaire. J Adolesc. 1995;18(2):179-192.

63. Parker G, Tupling H, Brown LB. Parental bonding instrument. Br J Med Psychol. 1979;52:1-10.

64. Picardi L, Tarsitani A, Toni A, et al. Validity and reliability of the Italian version of the Measure of Parental Style (MOPS). J Psychopathol. 2005;19:54-59.

65. Scrimali T. Il Vincolo della Dipendenza. Un modello cognitivista e complesso per le dipendenze patologiche e la loro terapia [The Constraint of Dependence. A Cognitive and Complex Model for Pathological Addictions and their Treatment]. Milano: Franco Angeli. 2011: 19-30. Italian.

66. Lemam J. From Challenging Culture to Challenged Culture: The Sicilian Cultural Code and the Socio-cultural Praxis of Sicilian Immigrants in Belgium. Belgium: Leuven University Press; 1987: 38-52.

67. Fazio I. The family, honour and gender in Sicily: models and new research. Modern Italy. 2004;9(2):263-280.

68. Carlestal E. La Famiglia - The Ideology of Sicilian Family Networks [dissertation]. 2005;3:227. Available from: https://www.diva-portal. org/smash/get/diva2:165796/FULLTEXT01.pdf.

69. Michaud PA, Blum RW, Slap GB. Cross-cultural surveys of adolescent health and behavior: progress and problems. Soc Sci Med. 2001; 53(9):1237-1246

70. Iacolino C, Pellerone M, Pace U, Ramaci T, Castorina V. Family Functioning and Disability: a Study on Italian Parents of Disabled Children. European Proceedings of Social and Behavioural Sciences. 2016;8:39-52

71. Wiles NJ, Lingford-Hughes A, Daniel J, et al. Socio-economic status in childhood and later alcohol use: a systematic review. Addiction. 2007; 102(10):1546-1563.

72. Kuendig H, Plant ML, Plant MA, et al. Beyond drinking: differential effects of demographic and socioeconomic factors on alcohol-related adverse consequences across European countries. Eur Addict Res. 2008; 14(3):150-160.

73. Lemstra M, Bennett NR, Neudorf C, et al. A meta-analysis of marijuana and alcohol use by socio-economic status in adolescents aged 10-15 years. Can J Public Health. 2008;99(3):172-177.

74. Ramaci T, Pellerone M, Iacolino C. Stress-related diseases: significant influence on the quality of life at workplaces. European Proceedings of Social and Behavioural Sciences. 2016;8:29-38.

75. Syed M, Seiffge-Krenke I. Personality development from adolescence to emerging adulthood: linking trajectories of ego development to the family context and identity formation. J Pers Soc Psychol. 2013;104(2): 371-384.

76. Clark DB, Thatcher DL, Maisto SA. Supervisory neglect and adolescent alcohol use disorders: effects on AUD onset and treatment outcome. Addict Behav. 2005;30(9):1737-1750.

77. Feldestein SW, Miller WR. Substance use and risk-taking among adolescents. J Ment Health. 2006;15(6):633-643.

78. Dishion TJ, Nelson SE, Kavanagh K. The family check-up with highrisk young adolescents: preventing early-onset substance use by parent monitoring. Behav Ther. 2003;34(4):553-571.

79. Dishion TJ, Andrews DW. Preventing escalating problem behaviors with high-risk young adolescents: immediate and 1-year outcomes. J Consult Clin Psychol. 1995;63(4):538-548. 


\section{Publish your work in this journal}

Neuropsychiatric Disease and Treatment is an international, peerreviewed journal of clinical therapeutics and pharmacology focusing on concise rapid reporting of clinical or pre-clinical studies on a range of neuropsychiatric and neurological disorders. This journal is indexed on PubMed Central, the 'PsycINFO' database and CAS,

and is the official journal of The International Neuropsychiatric Association (INA). The manuscript management system is completely online and includes a very quick and fair peer-review system, which is all easy to use. Visit http://www.dovepress.com/testimonials.php to read real quotes from published authors.

Submit your manuscript here: http://www.dovepress.com/neuropsychiatric-disease-and-treatment-journal 